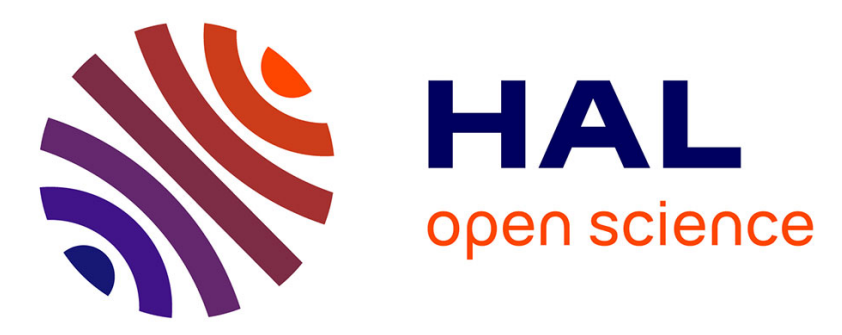

\title{
Improvement in the tribological performance of polycarbonate via the incorporation of molybdenum disulfide particles
}

Basma Ben Difallah, Mohamed Kharrat, M Dammak, Guy Monteil

\section{- To cite this version:}

Basma Ben Difallah, Mohamed Kharrat, M Dammak, Guy Monteil. Improvement in the tribological performance of polycarbonate via the incorporation of molybdenum disulfide particles. Tribology Transactions, 2014, 57, pp.806 - 813. hal-02300219

\section{HAL Id: hal-02300219 \\ https://hal.science/hal-02300219}

Submitted on 29 Sep 2019

HAL is a multi-disciplinary open access archive for the deposit and dissemination of scientific research documents, whether they are published or not. The documents may come from teaching and research institutions in France or abroad, or from public or private research centers.
L'archive ouverte pluridisciplinaire HAL, est destinée au dépôt et à la diffusion de documents scientifiques de niveau recherche, publiés ou non, émanant des établissements d'enseignement et de recherche français ou étrangers, des laboratoires publics ou privés. 


\section{IMPROVEMENT IN THE TRIBOLOGICAL PERFORMANCE OF POLYCARBONATE VIA THE INCORPORATION OF MOLYBDENUM DISULPHIDE PARTICLES}

\begin{tabular}{|r|l|}
\hline Journal: & Tribology Transactions \\
\hline Manuscript ID: & UTRB-1307.R2 \\
\hline Manuscript Type: & Manuscript for Publication Only \\
\hline Date Submitted by the Author: & 22-Mar-2014 \\
\hline Complete List of Authors: & $\begin{array}{l}\text { Ben Difallah, Basma; Ecole Nationale d'Ingénieurs de Sfax, Laboratoire des } \\
\text { Systèmes Electromécaniques } \\
\text { Kharrat, Mohamed; Ecole Nationale d'Ingénieurs de Sfax, Laboratoire des } \\
\text { Systèmes ElectroMécaniques } \\
\text { Dammak, Maher; Ecole Nationale d'Ingénieurs de Sfax, Laboratoire des } \\
\text { Systèmes Electromécaniques } \\
\text { Monteil, Guy; Ecole Nationale Supérieure de Mécanique et des } \\
\text { Microtechniques, Laboratoire FEMTO-ST }\end{array}$ \\
\hline Keywords: & $\begin{array}{l}\text { Polymers (solid) < Materials, Solid Lubricants < Solid/Self Lubrication, } \\
\text { Molybdenum Disulfide < Solid/Self Lubrication, Abrasive Wear < Wear, } \\
\text { Adhesive Wear < Wear }\end{array}$ \\
\hline
\end{tabular}

\section{SCHOLARONE"}

Manuscripts 


\title{
IMPROVEMENT IN THE TRIBOLOGICAL PERFORMANCE OF
} POLYCARBONATE VIA THE INCORPORATION OF MOLYBDENUM DISULPHIDE PARTICLES

\author{
B. BEN DIFALLAH ${ }^{1,2,3}$, M. KHARRAT ${ }^{1,4^{*}}$, M. DAMMAK $^{1,4}$ and G. MONTEIL $^{3}$ \\ ${ }^{1}$ Laboratoire des Systèmes Electromécaniques, Ecole Nationale d'Ingénieurs de Sfax, Route de Soukra km 3,5, \\ B.P. 1173,3038 Sfax, Tunisia \\ ${ }^{2}$ Institut Supérieur des Sciences Appliquées et de Technologie de GAFSA, Campus Universitaire Sidi Ahmed \\ Zarrouk, 2112 Gafsa, Tunisia \\ ${ }^{3}$ Laboratoire FEMTO-ST, Ecole Nationale Supérieure de Mécanique et des Microtechniques, 26 Rue de \\ l'épitaphe 25030 Besançon, France \\ ${ }^{4}$ Institut Préparatoire aux Etudes d'Ingénieurs de Sfax, Rte Menzel Chaker Km 0,5, B.P. 1172, 3018 Sfax, \\ Tunisia
}

\begin{abstract}
* To whom correspondence should be addressed at: Laboratoire des Systèmes Electromécaniques, Ecole Nationale d'Ingénieurs de Sfax, Route de Soukra km 3,5,

B.P. 1173, 3038 Sfax, Tunisia

Email : mohamed.kharrat@ipeis.rnu.tn
\end{abstract}




\begin{abstract}
The present study undertakes the assessment of the effect of the incorporation of molybdenum disulphide $\left(\mathrm{MoS}_{2}\right)$ flakes on the tribological behavior of polycarbonate (PC) matrix. Five weight ratios of the $\mathrm{MoS}_{2}$ particles in the PC matrix were considered in the range of $0-10$ wt $\%$. The composites were developed by direct injection molding. The determination of various tribological parameters after wear testing (the friction coefficient, the wear volume loss and the profilometric traces) and microscopical observations by scanning electron microscopy (SEM) were combined in an attempt to understand the effect of the solid lubricant in the composites' tribological performance. It was found that the tribological properties were improved by the addition of $\mathrm{MoS}_{2}$ particles. The maximum reductions in the friction coefficient and wear were obtained with $\mathrm{MoS}_{2}$ mass content about 7 to $10 \mathrm{wt} \%$. It seems that $\mathrm{MoS}_{2}$ decreases the polymer surface melting by dissipating the generated heat. Under sliding conditions, the incorporation of $\mathrm{MoS}_{2}$ particles enhances the abrasive component in the wear mechanism which is manifested by the formation of scratches in the two bodies in contact.
\end{abstract}

KEYWORDS: Polycarbonate; $\mathrm{MoS}_{2}$, Composite; Solid lubricant; Friction; Wear

$-2-$ 


\section{INTRODUCTION}

There is a great interest in the development of new polymer composites due to the various advantages, such as cost effectiveness, ease in manufacturing and excellent performance. Polymer composites are recommended in tribo-applications owing to the possibility of producing required material performance with judicious choice of fillers in adequate proportions in the composite. A great deal of research work has been carried out on thermoplastic composites based on layered solid lubricants such as graphite, molybdenum disulphide and boron nitride (Ben Difallah, et al. (1); Zhang, et al. (2); Suresha, et al. (3); Wang, et al. (4); Bijwe, et al. (5)). These studies have not only shown an improvement in the tribological performance of the composites depending on the nature and the amount of the solid lubricant, but also been significant in introducing such fillers to several industrial applications (Mnif, et al. (6); Deng, et al. (7); Cho, et al. (8)). The lubricant ability of the inclusions may provide better functioning by reducing friction and wear values.

Particularly, Bahadur and Gong (9) classified molybdenum disulphide $\left(\mathrm{MoS}_{2}\right)$ as one of the most common solid lubricant used. This material has a crystalline lamellar structure with hexagonal sulphur planes sandwiched between two hexagonal molybdenum layers. The atoms lying on the same crystal layer are strongly covalently bonded to each other. The layers themselves are bonded by weak van der Waals forces. Winer (10) reported that the lubrication capacity of $\mathrm{MoS}_{2}$, i.e. low friction characteristics and easy cleavage, is intrinsic to its layered structure. When added to thermoplastic polymers, $\mathrm{MoS}_{2}$ may enhance friction and wear properties (Bahadur and Gong (9); Pettarin, et al. (11); Zhu, et al. (12); Ben Difallah, et al. (13)). Bahadur and Gong (9) performed friction and wear tests on polyimide (PI), polyamide 6-6 (PA 66) and polytetrafluoethylene (PTFE) with $\mathrm{MoS}_{2}$ as a filler. On the one hand, they found that wear was considerably reduced, and on the other hand, they revealed that the wear resistance of composites was affected by the filler content. The wear rate of PA was minimum 
with an optimum content of $\mathrm{MoS}_{2}$ about 15-20 wt\%. Pettarin, et al. (11) found that the incorporation of $\mathrm{MoS}_{2}$ to high molecular weight high density polyethylene (HMW-HDPE) improves its abrasive wear and sliding performance with a content of $\mathrm{MoS}_{2}$ for minimum wear rate around $10 \mathrm{wt} \%$. They also reported that, under sliding conditions, the main wear mechanism of HMW-HDPE was changed from severe melting wear to mild adhesive wear. As for Zhu, et al. (12), they reported that $\mathrm{MoS}_{2}$ improved dry and water sliding wear rate of PI for an optimum content of $\mathrm{MoS}_{2}$ around 10-15 wt\%. In the same vein, we have published a previous work (13) dealing with the tribological behavior of two polymers composites filled with different weight fractions of $\mathrm{MoS}_{2}$. Conclusive results were found in order to improve the knowledge about the impact of the development methodology on the interfacial adhesion between the filler and the matrix. We concluded that the lubricating ability of $\mathrm{MoS}_{2}$ depends on the nature of the polymer, the development methodology and the interaction between the filler and the matrix.

Polycarbonate (PC) is an amorphous engineering thermoplastic polymer which combines transparency, good thermal stability, impact resistance and the easiness to be processed on conventional machinery. New PC composites are being developed in order to improve the tribological behavior of the base thermoplastic by using various fillers, such as zinc oxide $(\mathrm{ZnO})$, silicon dioxide $\left(\mathrm{SiO}_{2}\right)$, short glass fibers, ... (Carrión, et al. (14); Carrión, et al. (15); Carrión, et al. (16); Wang, et al. (17); Ho and Jeng (18)). Carrión, et al. studied the wear response of $\mathrm{PC}$ when $\mathrm{ZnO}$ nanoparticles and organoclays were added to the polymer (14)(16). By their research work, the authors confirmed the important reduction in the wear rate with respect to neat PC. As for Wang, et al. (17), they investigated the tribological performances of $\mathrm{PC}$ film and nano- $\mathrm{SiO}_{2} / \mathrm{PC}$ composite coating, which exhibited lower frictional coefficient. Concerning Ho and Jeng (18), they analyzed the wear behavior of PC reinforced with $20 \mathrm{wt} \%$ short glass fibers. The authors reported that the wear volume loss was 
significantly influenced by the fiber orientation according to the sliding direction.

Therefore, the fundamental apprehension of the role attributed to different fillers in tribological performance is essential for successful applications. Through this paper, studies are focused on the friction and wear properties of polycarbonate composites containing 2$10 \%$ of $\mathrm{MoS}_{2}$ powder. For this purpose, wear tests of the PC composites were performed using a ball on flat microtribometer. The results obtained could provide evidence to explain the changes in friction and wear mechanisms at various amounts of $\mathrm{MoS}_{2}$ particles.

\section{EXPERIMENTAL DETAILS}

\section{Materials and specimen preparation}

A commercial PC thermoplastic polymer was used as the matrix material. The PC pellets (with a diameter of approximately $2-3.5 \mathrm{~mm})$ were provided from Altech, $\left(1.20 \mathrm{~g} / \mathrm{cm}^{3}\right.$ density, $14 \mathrm{~g} / 10 \mathrm{~min} \mathrm{IF})$. A flaky-shaped $\mathrm{MoS}_{2}$ powder (6 $\mu \mathrm{m}$ average size, $5.06 \mathrm{~g} / \mathrm{cm}^{3}$ density) with 95\% purity was purchased from Aldrich Chemistry (Sigma-Aldrich) (Fig. 1). The considered weight fractions (wt \%) of $\mathrm{MoS}_{2}$ were $2 \%, 4 \%, 7 \%$ and $10 \%$. After being dried in a vacuum oven at $110{ }^{\circ} \mathrm{C}$ for $4 \mathrm{~h}$, PC was injection molded with $\mathrm{MoS}_{2}$ using DEMAG ERGOTECH 125/475 injection molding machine. Table 1 gives the injection parameters.

Fig.1. SEM image of the flake-shaped $\mathrm{MoS}_{2}$ particles, as supplied.

Table 1. Injection molding parameters of PC composites.

Figure 2 gives a typical scanning electron microscopy (SEM) image of the fractured surface of the $10 \mathrm{wt} \% \mathrm{MoS}_{2}-\mathrm{PC}$ composite. There is no sign of large agglomeration of the $\mathrm{MoS}_{2}$ particles. 
Fig 2. SEM picture of the fracture surface of a PC matrix composite containing $10 \mathrm{wt} \% \mathrm{MoS}_{2}$ flakes

\section{Friction and wear testing}

A specific home-made microtribometer was employed for friction and wear tests of the $\mathrm{PC} / \mathrm{MoS}_{2}$ composites. The apparatus is in a reciprocating ball on flat configuration. The composite flat specimens were rubbed against a 19-mm-diameter high chromium steel ball under a constant applied normal load of $5 \mathrm{~N}$. The tests were carried out for 10,000 cycles with the ball oscillating at a frequency of $1 \mathrm{~Hz}$ over a displacement magnitude of $2 \mathrm{~mm}$. At least, three friction and wear tests were conducted for each composite. Figure 3 shows the used microtribometer which can be divided into three functional sub-systems. Concerning the first one, it is the mechanical arrangement (measuring head) generating the required contact load (normal load) between the high chromium steel ball and the flat composite sample and allowing the tangential load to be monitored using a piezoelectric sensor. The measuring head is equilibrated by a counterbalancing arm allowing the magnitude of the dead load to be adjusted to very low values. As for the second sub-system, it is the micro-displacement arrangement based upon a translation table with a precise linear ball bearing. This table is coupled to a step-by-step motor using a ball screw. With regard to the third sub-system, it is a control and data acquisition unit used for driving the microtribometer and for data acquisition and processing. The treatment of the measurements and the display of the results are performed by PC-based software.

The volume of each wear scar was measured using the optical 3D surface metrology software program provided by an Infinitefocus Alicona ${ }^{\circledR}$ laboratory system. To eliminate the influence of debris on wear volume measurements, the samples were ultrasonically cleaned. Optical

$-6-$ 
Scanning Microscopy (OSM) technique was also used to explore the worn surface. $\mathrm{PC} / \mathrm{MoS}_{2}$ composites wear mechanisms were analyzed using SEM, JEOL JSM 6400F. The surface of the sample was coated with gold before SEM observation.

Fig. 3. Schematic representation of the ball on flat microtribometer.

\section{RESULTS AND DISCUSSION}

\section{Friction testing results}

Figure 4 displays typical evolutions of the friction coefficient with the number of sliding cycles for PC/MoS 2 composites. The curves of friction coefficient are composed of two main stages; the first one is the running-in stage during which the friction coefficient sharply increases until it reaches a maximum value, and the second one is the steady-state stage where the friction coefficient is stabilized and remains constant as function of the number of sliding cycles. In the second stage of sliding, it seems that the stabilized value of the friction coefficient decreases with the increase of the $\mathrm{MoS}_{2}$ content.

Fig. 4. Typical evolutions of the friction coefficient versus the number of cycles for $\mathrm{PC} / \mathrm{MoS}_{2}$ composites containing different $\mathrm{wt} \% \mathrm{MoS}_{2}$.

The variations of the friction coefficient with $\mathrm{MoS}_{2}$ content after 10,000 sliding cycles are better shown in Figure 5. The mean friction coefficient decreases with the increase in the filler content. In fact, it falls from about 0.70 to 0.61 when the $\mathrm{MoS}_{2}$ mass content increases from 0 wt $\%$ to only $2 \mathrm{wt} \%$, whereas, it drops to 0.54 at $10 \mathrm{wt} \%$ of $\mathrm{MoS}_{2}$. In this case, the reduction in the friction coefficient is about 0.16 over the range of $0-10 \mathrm{wt} \%$ of the $\mathrm{MoS}_{2}$ inclusions. The

$$
-7-
$$


solid lubricant filler can substantially affect the friction behavior of the PC matrix. The better response corresponds to $10 \mathrm{wt} \%$ of $\mathrm{MoS}_{2}$.

Fig. 5. Evolution of the mean friction coefficient versus the $\mathrm{MoS}_{2}$ mass content after 10,000 sliding cycles for $\mathrm{PC} / \mathrm{MoS}_{2}$ composites. Good test reproducibility was achieved. Error bars reveal a small amount of variability among the mean friction coefficients.

\section{Wear test results}

We have measured the wear on different composites after 10,000 sliding cycles by using the 3D metrology device Infinitefocus. Table 2 contains the 2D transversal profiles recorded at the middle of the wear track and the typical 3D datasets registered on the wear areas. The 3D projections have been reconstructed by a precision optic allowing a complete detection of the surface with a vertical resolution of $500 \mathrm{~nm}$. The goal is to trace microgeometry changes on composite surfaces after wear sliding tests.

Table 2. Typical transversal profiles and three dimensional images recorded on the worn surfaces of the PC composites with different amounts of $\mathrm{MoS}_{2}$ fillers after 10,000 sliding cycles.

For the neat PC, positive reliefs were observed over the whole sliding track. Interestingly, adding $2 \mathrm{wt} \%$ of $\mathrm{MoS}_{2}$ changed the surface morphology. Topographic scans of the composite show material removal inside the wear scar and the formation of plough areas. The same trends can be seen with the other filler fractions. Wear peaks seem to be much shallower and less abundant as the fillers content increases. Thus, a finer pattern is generated with the addition of $\mathrm{MoS}_{2}$ flakes. This was further confirmed by the $2 \mathrm{D}$ transversal wear profile of PC and its composites. The plot of the PC 2D profile shows evident positive reliefs along the $-8-$ 
wear track. The irregular surface is occupied by molten wear debris which were extracted and re-deposited onto the polycarbonate surface. The wear profile becomes totally different when $2 \mathrm{wt} \%$ of $\mathrm{MoS}_{2}$ is added. In fact, it exhibits almost negative reliefs. Besides, the width and depth of wear tracks are gradually smaller with the increase of $\mathrm{MoS}_{2}$ amount.

Further wear parameters can be specified from the surface topography data. For each $\mathrm{PC} / \mathrm{MoS}_{2}$ composite specimen, the wear volume loss is estimated as the difference between the grooved volume $\left(\mathrm{V}^{-}\right)$and the pile-up volume $\left(\mathrm{V}^{+}\right)$which are defined in the schematic representation in Figure 6 (Cayer-Barrioz, et al. (19)).

Fig. 6. Schematic representation of wear profile groove on a composite surface after the sliding test.

Figure 7 illustrates the evolutions of the measured grooved volume $\left(\mathrm{V}^{-}\right)$, the measured pile-up volume $\left(\mathrm{V}^{+}\right)$(Fig. 7-a) and the difference between them representing the wear volume loss (Fig. 7-b) as function of the filler content. It can be seen that both of the grooved and the pileup volumes were reduced when $\mathrm{MoS}_{2} \mathrm{wt} \%$ is increased. However, the pile-up volume was immediately affected by the incorporation of $2 \mathrm{wt} \%$ of $\mathrm{MoS}_{2}$. It falls from $0.0072 \mathrm{~mm}^{3}$ to $0.0056 \mathrm{~mm}^{3}$ when the content of $\mathrm{MoS}_{2}$ is $2 \mathrm{wt} \%$. Molybdenum disulphide inclusions proved beneficial in reducing the severe adhesive component of the PC wear. On the other hand, the grooved volume $\left(\mathrm{V}^{-}\right)$of the different composites shows lower values than the pure PC. It falls from $0.0112 \mathrm{~mm}^{3}$ with pure PC to $0.0068 \mathrm{~mm}^{3}$ with $\mathrm{PC}$ composite at $10 \mathrm{wt} \%$ of $\mathrm{MoS}_{2}$. Therefore, with the rise of $\mathrm{MoS}_{2}$ content, the wear volume loss of the composites increased from about $0.0040 \mathrm{~mm}^{3}$ for pure PC to $0.0051 \mathrm{~mm}^{3}$ for $2 \mathrm{wt} \% \mathrm{MoS}_{2}$ flakes-filled PC composites. From this point, the wear volume of the composites rapidly falls with the increase of the filler content. A minimum value of $0.0022 \mathrm{~mm}^{3}$ is reached with $10 \mathrm{wt} \%$ of $\mathrm{MoS}_{2}$. It is 
clear that the wear resistance of PC is greatly enhanced by the addition of $\mathrm{MoS}_{2}$ fillers. In addition, it can be established that pure PC has a relatively low initial wear associated with large particles adhering to the specimen surface and thus increasing the pile-up volume $(\mathrm{V}+)$.

Fig. 7. Evolution of the wear characteristics of $\mathrm{PC} / \mathrm{MoS}_{2}$ composites versus the $\mathrm{MoS}_{2}$ mass content after 10,000 sliding cycles: (a) grooved volume $\left(\mathrm{V}^{-}\right)$and pile-up volume $\left(\mathrm{V}^{+}\right)$, (b) resulting wear volume losses. Good agreement is achieved in the experimental values of the measured volumes. In all cases, the average error percentages did not exceed $14 \%$ when measuring the mean volume values.

In order to enhance the analysis of the composites worn surfaces, three-dimensional wear track profiles were developed under an Optical Scanning Microscope (OSM). Figure 8 gives typical profiles obtained on specimens tested for 10,000 sliding cycles for the neat PC and the PC with 10 wt $\% \mathrm{MoS}_{2}$. The wear track of the unfilled PC is obviously not uniform, showing severe plastic deformation of the neat polymer (Fig. 8-a). Nevertheless, with filling $10 \mathrm{wt} \%$ of $\mathrm{MoS}_{2}$ to the matrix polymer (Fig. 8-b), the wear track of the composite seems to be smoother and more uniform with the presence of light scratches. These results satisfy, with a larger set of observations, the information obtained in Table 2.

Fig. 8. Three dimensional profiles recorded on the worn surfaces after 10,000 sliding cycles (OSM): (a) unfilled PC, (b) PC+ $10 \mathrm{wt} \% \mathrm{MoS}_{2}$.

\section{Analysis of wear mechanisms}

Figure 9 presents different optical micrographs showing the overall view of typical welldeveloped wear scars of PC composites with various amounts of $\mathrm{MoS}_{2}$ filler. The neat PC

$-10-$ 
wear scar (Fig. 9-a) is characterized by material movements and a large amount of plastic deformations. The figures in the middle and in the right side correspond to the PC composite wear scars with 4 and $10 \mathrm{wt} \% \mathrm{MoS}_{2}$, respectively (Fig. 9-b and c). The unworn surface of the unfilled PC is different from that of PC composites. Actually, the PC surface is uniform, and the scratches left after the injection molding operation are barely seen. On the contrary, the observations of PC composites indicate the presence of irregular topographic features on the unworn parts. Furthermore, abrasive grooves are clearly seen in the two worn surfaces. Nevertheless, the wear scar width seems to be much narrower with $10 \mathrm{wt} \%$ of $\mathrm{MoS}_{2}$. The incorporation of $\mathrm{MoS}_{2}$ inclusions to the $\mathrm{PC}$ matrix resulted in further improvement of the tribological properties owing to mild abrasion of $\mathrm{MoS}_{2}$ fillers. This is probably due to the formation of an interphase layer of wear debris between the two bodies in contact (Zhang, et al. (20)).

Fig. 9. Optical observations of the different PC composites after wear tests.

For a further understanding of the wear mechanisms, SEM micrographs were also recorded in order to manifest the final worn conditions. Figure 10 shows SEM micrographs of the PC worn surface and its counterpart. As expected, PC surface is rough (Fig. 10-a) and covered by wear particles, thus forming adherent agglomerate (Scott (21)). At higher magnifications (Fig. 10-b), the SEM micrograph clearly shows accumulated wear particles under the repeated sliding cycles. As per Arribas et al. (22), the generated wear debris gets entrapped in the contact region and forms an adherent layer with the production of severely plastically deformed material at the tip of the wear scar. Figures 10-c and d show representative samplings of the high chromium steel ball tested against neat PC at two different magnifications. The worn surface is almost not damaged and is surrounded by large plate-like

$$
-11-
$$


wear debris. Their size is in the order of several tens of micrometers in the in-plane dimensions (Fig. 10-d). Consistent with the results reported elsewhere (Carrión, et al. (16)), the unfilled PC is shown to have poor tribological performance characterized by severe damage originally caused by the production of a large amount of wear particles in an adhesive-abrasive wear mechanism.

Fig. 10. SEM micrographs of the worn surface in the unfilled PC (a) and (b); and its counterpart (c) and (d), 10,000 cycles.

The micrograph presented in Figure 11 shows the worn surface of PC composite with $10 \mathrm{wt} \%$ of $\mathrm{MoS}_{2}$ and its counterpart. The wear scar of the composite specimen appears smooth and relatively uniform with the presence of fine scratches (Fig. 11-a). At higher magnifications, the micrograph reveals the existence of large debris patches attached at the extremity of the wear track. The formed layer of plastically deformed material seems to be thinner and less adherent compared with that of PC sample (Fig. 11-b). The SEM micrographs of the corresponding pin counterpart are shown in Figure 11-c and 11-d, respectively. The worn surface of the steel counterpart shows a large amount of transferred wear debris (Fig. 11-c). It can also be seen that a thick and not uniform film was clearly formed showing slight abrasive scratches (Fig. 11-d). This non-coherent film is controlled by softening and solid lubricant supply. Softening mechanisms result in discontinuous transfer particles (Samyn, et al. (23)). According to Lancaster (24), this mechanism is attributed to reducing interaction between counterface roughness and polymer sample (Lancaster (24)). It can be established that the incorporation of $\mathrm{MoS}_{2}$ flakes promotes the change of the wear mechanism from adhesion to abrasion since it has been run with other fillers (Carrión, et al. (14); Arribas, et al. (22)). In this case, several previous studies have focused on the great influence of wear particles during

$-12-$ 
friction process (Zum Gahr (25); Bourithis, et al. (26)). Depending on their physicochemical properties, their size and shape, third body wear particles may lead to abrasive wear mechanism. In the case of the unfilled polycarbonate, severe surface damages characterized by wear debris detachment in a massive quantity were developed (Carrión; et al. (16); Lee, et al. (27)). Under the repeated sliding cycles, serious plastic deformations and subsequent energy dissipation lead to the adhesion of wear particles and thus to a severe wear mechanism. On the contrary, the incorporation of $\mathrm{MoS}_{2}$ flakes to the PC matrix seems to change the wear mode into a predominant abrasive one. In fact, it was clearly seen that fine rays were developed in the composite worn surface, furthermore, the number of adherent wear particles decreased significantly. Pettarin, et al. (11) reported that the addition of commercial $\mathrm{MoS}_{2}$ to HMW-HDPE matrix contribute to enhance the generated heat dissipation, thus it inhibits the surface melting of the polymer (Pettarin, et al. (11)). Consequently, the wear resistance performance of HMW-HDPE was improved by the incorporation of $\mathrm{MoS}_{2}$.

Fig. 11. SEM micrographs of the worn surface in the PC composite with $10 \mathrm{wt} \% \mathrm{MoS}_{2}$ (a) and (b); SEM micrographs of the transfer film on the counterpart (c) and (d), 10,000 cycles.

\section{CONCLUSIONS}

In this study, the tribological characteristics of $\mathrm{PC} / \mathrm{MoS}_{2}$ composites were investigated using a ball on flat microtribometer. The experimental results indicated that the unfilled PC has a poor tribological performance characterized by the formation of layered particle debris in some parts of the polymer wear track. In this case, the sheared bodies in contact are put down again while the strength of wear particles is much poorer. Opportunities provided by visual display revealed that severe adhesive/abrasive wear mechanism coupled with serious plastic deformations occurred in the unfilled polymer. The incorporation of $\mathrm{MoS}_{2}$ flakes improved

$-13-$ 
the polymer tribological performances by reduction of friction and wear. The abrasive component of wear took a dominant place by the addition of $\mathrm{MoS}_{2}$ particles. It was reported in a previous research work that the weak bonds between the filler and the matrix cause the polymer fracture and the detachment of $\mathrm{MoS}_{2}$ particles in the sliding trace (Ben Difallah et al., (13)). By this way, polymer heating under sliding cycles could be restrained. This result has confirmed the hypothesis that the $\mathrm{MoS}_{2}$ filler was responsible of decreasing thermal conductivity in various thermoplastic polymers by the increase in heat dissipation during the sliding tests.

\section{ACKNOWLEDGEMENTS}

The authors would gratefully acknowledge the financial assistance of the Electro-Mechanical Systems Laboratory in the National Engineering School of Sfax funded by the Ministry of Higher Education and Scientific Research of TUNISIA as well as the assistance provided by the Department of Applied Mechanics in the FEMTO-ST Institute at Besançon-FRANCE. Thanks should also be extended to the members of the Polymer Processing Center of SousseTUNISIA for their help in samples preparation.

\section{REFERENCES}

(1) Ben Difallah, B., Kharrat, M., Dammak, M. and Monteil, G. (2012), "Mechanical and tribological response of ABS polymer matrix filled with graphite powder," Mater. Des. 34, pp. $782-787$.

(2) Zhang, X.R., Pei, X.Q. and Wang, Q.H. (2009), "Friction and wear studies of polyimide composites filled with short carbon fibers and graphite and micro $\mathrm{SiO}_{2}$," Mater. Des. 30, 10, pp. 4414-4420.

(3) Suresha, B., Chandramohan, G., Renukappa, M.N. and Siddaramaiah (2007), "Mechanical

$-14-$ 
and tribological properties of glass-epoxy composites with and without graphite Particulate Filler,” J. Appl. Polym. Sci. 103, 4, pp. 2472-2480.

(4) Wang, Q., Zhang, X. and Pei, X. (2010), “Study on the synergistic effect of carbon fiber and graphite and nanoparticle on the friction and wear behavior of polyimide composites," Mater. Des. 31, 8, pp. 3761-3768.

(5) Bijwe, J., John Rajesh, J., Jeyakumar, A., Ghosh, A. and Tewari, U.S. (2000), "Influence of solid lubricants and fibre reinforcement on wear behaviour of polyethersulphone," Tribol. Int. 33, 10, pp. 697-706.

(6) Mnif, R. Ben Jemaa, M.C. Hadj Kacem, N. and Elleuch, R. (2013), "Impact of Viscoelasticity on the Tribological Behavior of PTFE Composites for Valve Seals Application”, Tribol. Trans. 56, 5, pp. 879-886.

(7) Deng, J., Song, W., Zhang, H., Yan, P. and Liu, A. (2011), "Friction and wear behaviors of the carbide tools embedded with solid lubricants in sliding wear tests and in dry cutting processes,” Wear 270, 9-10, pp. 666-674.

(8) Cho, M.H., Ju, J., Kima, S.J. and Jang, H. (2006), “Tribological properties of solid lubricants (graphite, $\mathrm{Sb}_{2} \mathrm{~S}_{3}, \mathrm{MoS}_{2}$ ) for automotive brake friction materials," Wear 260, 7-8, pp. 855-860.

(9) Bahadur, S. and Gong, D. (1992), "The action of fillers in the modification of the tribological behavior of polymers," Wear 158, 1-2, pp. 41-59.

(10) Winer, W.O. (1967), "Molybdenum disulphide as a lubricant: a review of fundamental knowledge," Wear 10, 6, pp. 422-452.

(11) Pettarin, V., Churruca, M. J., Felhös, D., Karger-Kocsis, J. and Frontini, P.M. (2010), "Changes in tribological performance of high molecular weight high density polyethylene induced by the addition of molybdenum disulphide particles," Wear 269, 1-2, pp. 31-45.

(12) Zhu, P., Wang, X., Wang, X.D., Huang, P. and Shi, J. (2006), “Tribology performance of 
molybdenum disulphide reinforced thermoplastic polyimide under dry and water lubrication conditions," Ind. Lubr. Tribol. 58, 4, pp. 195-201.

(13) B. Ben Difallah, M. Kharrat, M. Dammak and G. Monteil, (2012), "Microstructure, friction and wear analysis of thermoplastic based composites with solid lubricant", Mechanics \& Industry 13, 5, pp.337-346.

(14) Carrión, F.J., Sanes, J. and Bermúdez, M.D. (2007), "Influence of ZnO nanoparticle filler on the properties and wear resistance of polycarbonate," Wear 262, 11-12, pp. 1504-1510.

(15) Carrión, F.J., Sanes, J. and Bermúdez, M.D. (2007), "Effect of ionic liquid on the structure and tribological properties of polycarbonate-zinc oxide nanodispersion," Mater. Lett. 61, 23-24, pp. 4531-4535.

(16) Carrión, F.J., Arribas, A., Bermúdez, M.D. and Guillamon, A. (2008), "Physical and tribological properties of a new polycarbonate-organoclay nanocomposite," Euro. Polym. J. 44, 4, pp. 968-977.

(17) Wang, Z.Z., Gu, P. and Zhang, Z. (2010), "Indentation and scratch behavior of nano$\mathrm{SiO}_{2}$ /polycarbonate composite coating at the micro/nano-scale," Wear 269, 1-2, pp. 21-25.

(18) Ho, K.C. and Jeng, M.C. (1997), "Tribological characteristics of short glass fibre reinforced polycarbonate Composites," Wear 206, 1-2, pp. 60-68.

(19) Cayer-Barrioz, J., Mazuyer, D., Tonck, A., Kapsa, Ph. and Chateauminois, A. (2006), "Nano-scratch and friction: An innovative approach to understand the tribological behaviour of poly(amide) fibres,” Tribol. Int. 39, 2, pp. 62-69.

(20) Zhang, X., Liao, G., Jin, Q., Feng, X. and Jian, X. (2008), “On dry sliding friction and wear behavior of PPESK filled with PTFE and graphite," Tribol. Int. 41, 3, pp. 195-201.

(21) Scott, F.H. (2002), "High-temperature sliding wear of metals," Tribol. Int. 35, 8, pp. $489-495$.

(22) Arribas, A., Bermúdez, M.D., Brostow, W., Carrión-Vilches, F.J. and Olea-Mejía, O.

$-16-$ 
1

2

3

4

5

8

10

(2009), "Scratch resistance of a polycarbonate + organoclay nanohybrid," Express Polym. Lett. 3, pp. 621-629.

(23) Samyn, P., De Baets, P., Schoukens, G. and Van Driessche, I. (2007), "Friction, wear and transfer of pure and internally lubricated cast polyamides at various testing scales," Wear $\mathbf{2 6 2}$, 11-12, pp. 1433-1449.

(24) Lancaster, J.K. (1975), “Geometrical effects on wear of polymers and carbons,” J. Lubr. Technol. 97, pp. 187-194.

(25) Zum Gahr, K.H. (1998), “Wear by hard particles,” Tribol. Int. 31, 10, pp. 587-596.

(26) Bourithis, L., Papaefthymiou, S. and Papadimitriou, G.D. (2002), "Plasma transferred arc boriding of a low carbon steel: microstructure and wear properties,” Appl. Surf. Sci. 200, 1-4, pp. 203-218.

(27) Lee, J.H., Xu, G.H. and Liang, H. (2001), "Experimental and numerical analysis of friction and wear behavior of polycarbonate," Wear 251, 1-12, pp. 1541-1556. 


\section{Table captions}

Table 1. Injection molding parameters of PC composites.

Table 2. Typical transversal profiles and three dimensional images recorded on the worn surfaces of the PC composites with different amounts of $\mathrm{MoS}_{2}$ filler after 10,000 sliding cycles.

$-18-$

http://mc.manuscriptcentral.com/tandf/tribtrans, E-mail: FSadeghi@stle.org 


\section{Figure captions}

Fig. 1. SEM image of $\mathrm{MoS}_{2}$ powder, as supplied.

Fig 2. SEM picture of the fracture surface of a PC matrix composite containing $10 \mathrm{wt} \% \mathrm{MoS}_{2}$ flakes.

Fig. 3. Schematic representation of the ball on disk microtribometer.

Fig. 4. Typical evolutions of the friction coefficient versus the number of cycles for $\mathrm{PC} / \mathrm{MoS}_{2}$ composites containing different $\mathrm{wt} \% \mathrm{MoS}_{2}$.

Fig. 5. Evolution of the mean friction coefficient versus the $\mathrm{MoS}_{2}$ mass content after 10,000 sliding cycles for $\mathrm{PC} / \mathrm{MoS}_{2}$ composites. Good test reproducibility was achieved. Error bars reveal a small amount of variability among the mean friction coefficients.

Fig. 6. Schematic representation of wear profile groove on a composite surface after the sliding test.

Fig. 7. Evolution of the wear characteristics of $\mathrm{PC} / \mathrm{MoS}_{2}$ composites versus the $\mathrm{MoS}_{2}$ mass content after 10,000 sliding cycles: (a) grooved volume $\left(\mathrm{V}^{-}\right)$and pile-up volume $\left(\mathrm{V}^{+}\right)$, (b) resulting wear volume losses. Good agreement is achieved in the experimental values of the measured volumes. In all cases, the average error percentages did not exceed $14 \%$ when measuring the mean volume values.

Fig. 8. Three dimensional profiles recorded on the worn surfaces after 10,000 sliding cycles (OSM): (a) unfilled PC, (b) PC+ $10 \mathrm{wt} \% \mathrm{MoS}_{2}$.

Fig. 9. Optical observations of the different PC composites after wear tests.

Fig. 10. SEM micrographs of the worn surface in the unfilled PC (a) and (b); and its counterpart (c) and (d), 10,000 cycles.

Fig. 11. SEM micrographs of the worn surface in the PC composite with 10 wt $\% \mathrm{MoS}_{2}$ (a) and (b); SEM micrographs of the transfer film on the counterpart (c) and (d), 10,000 cycles. 
Fig. 1

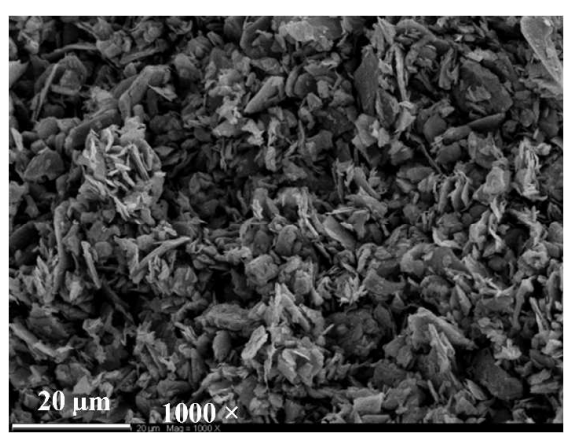

2

4

5

6

10

11

12

13

14

15

16

17

18

19

20

21

22

23

24

25

26

27

28

29

30

31

32

33

34

35

36

37

38

39

40

41

42

43

44

45

46

47

48

49

50

51

52

53

54

55

56

57

58

59

60

http://mc.manuscriptcentral.com/tandf/tribtrans, E-mail: FSadeghi@stle.org 


\section{Fig. 2}

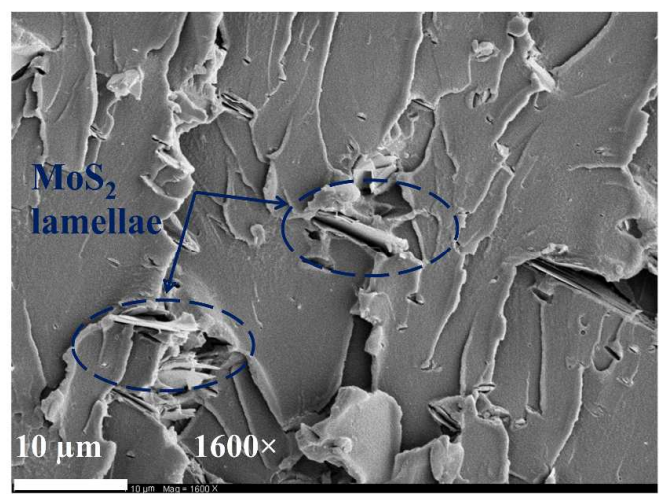


Fig. 3

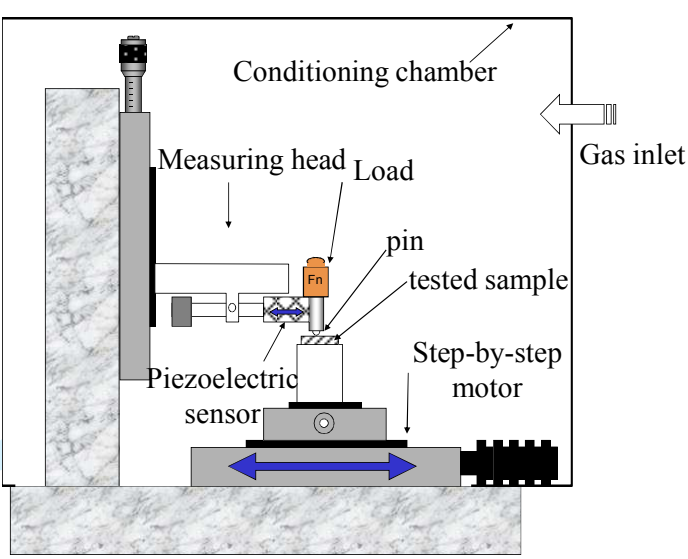

http://mc.manuscriptcentral.com/tandf/tribtrans, E-mail: FSadeghi@stle.org 


\section{Fig. 4}

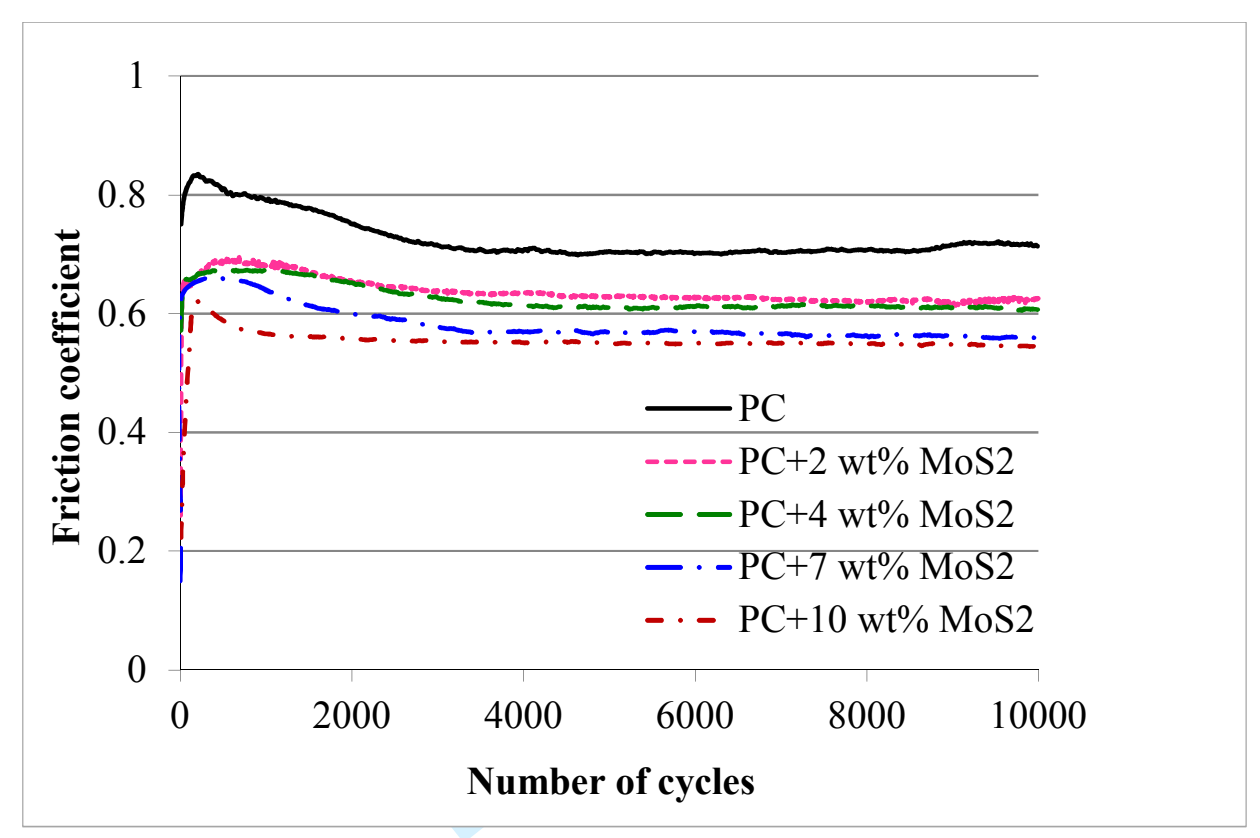

29

30

31

32

33

34

35

36

37

38

39

40

41

42

43

44

45

46

47

48

49

50

51

52

53

54

55

56

57

58

59

60

http://mc.manuscriptcentral.com/tandf/tribtrans, E-mail: FSadeghi@stle.org 


\section{Fig. 5}

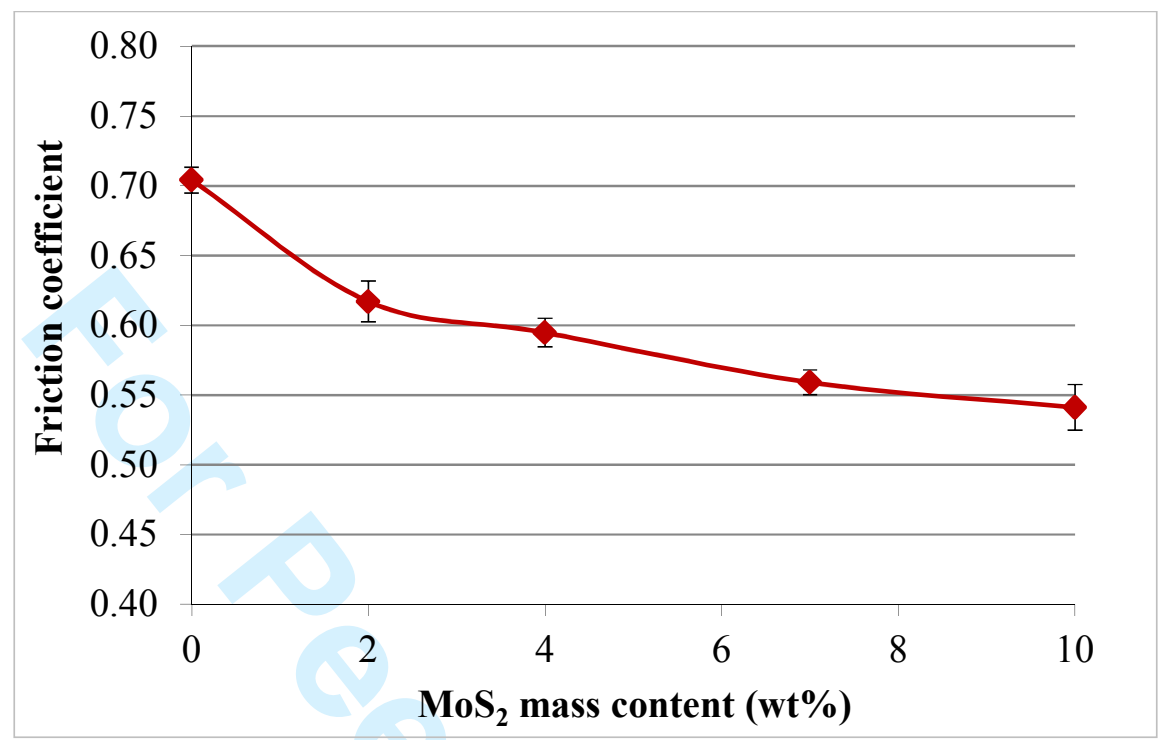

25 
Fig. 6

1

2

4

5

6

7

10

11

12

13

14

15

16

17

18

19

20

21

22

23

24

25

26

27

28

29

30

31

32

33

34

35

36

37

38

39

40

41

42

43

44

45

46

47

48

49

50

51

52

53

54

55

56

57

58

59

60

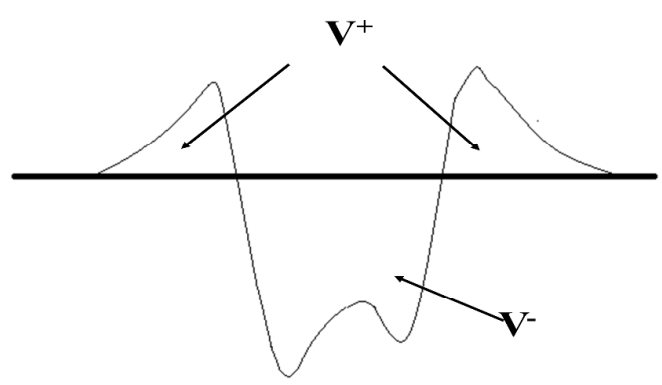

http://mc.manuscriptcentral.com/tandf/tribtrans, E-mail: FSadeghi@stle.org 


\section{Fig. 7}
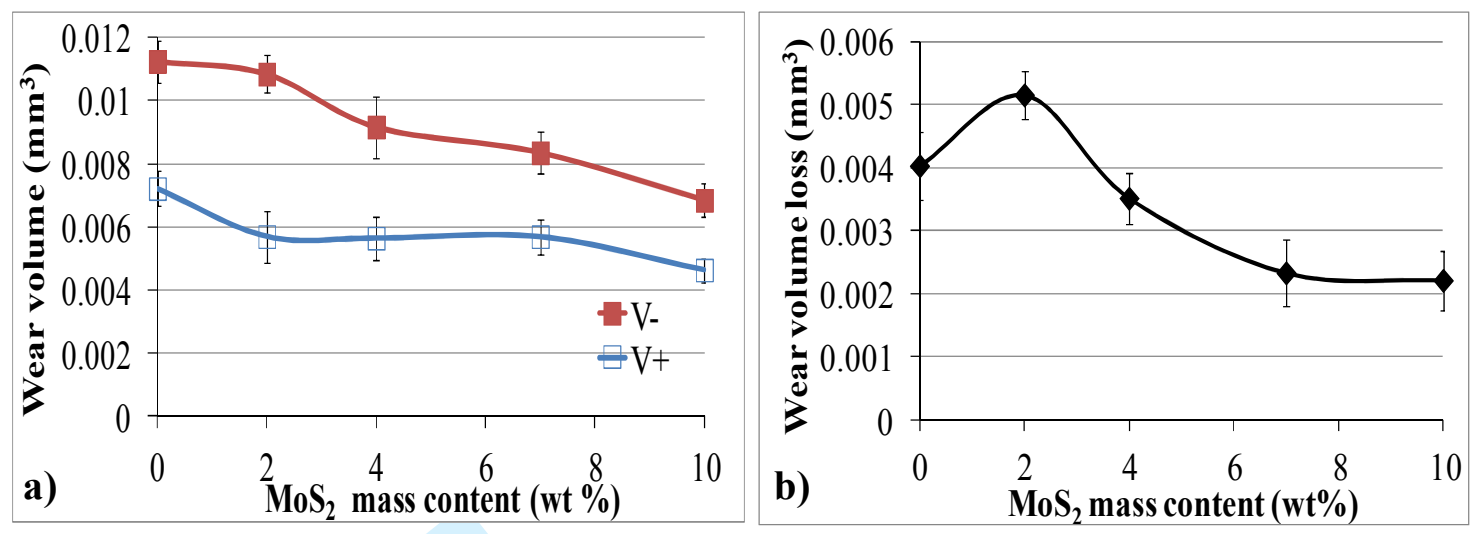

20

21

22

23

24

25

26

27

28

29

30

31

32

33

34

35

36

37

38

39

40

41

42

43

44

45

46

47

48

49

50

51

52

53

54

55

56

57

58

59

60

http://mc.manuscriptcentral.com/tandf/tribtrans, E-mail: FSadeghi@stle.org 
Fig. 8
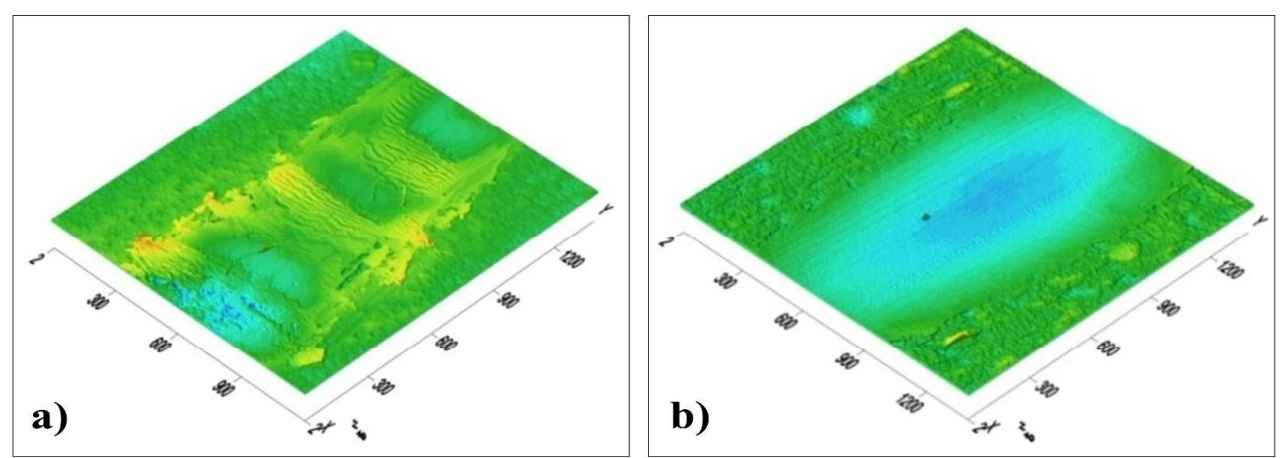

b) 
Fig. 9
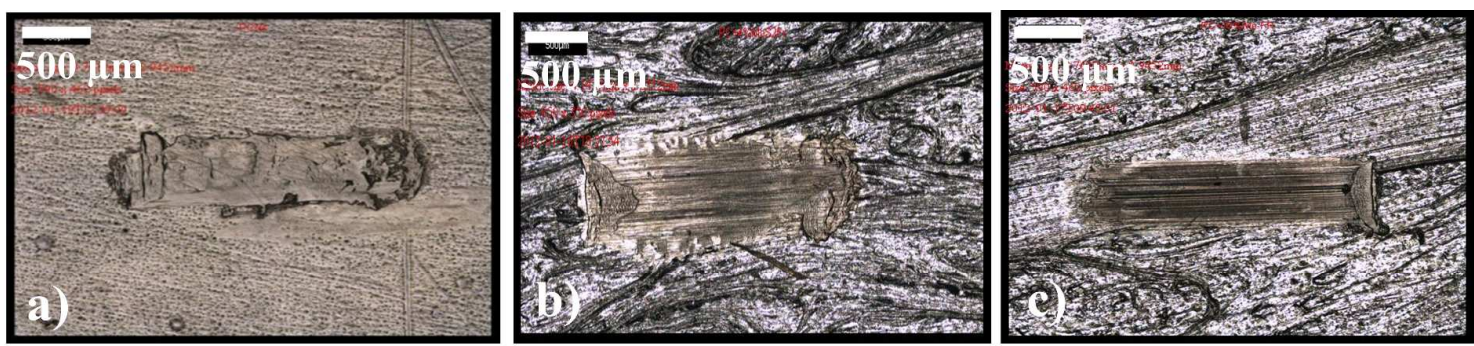
Fig. 10
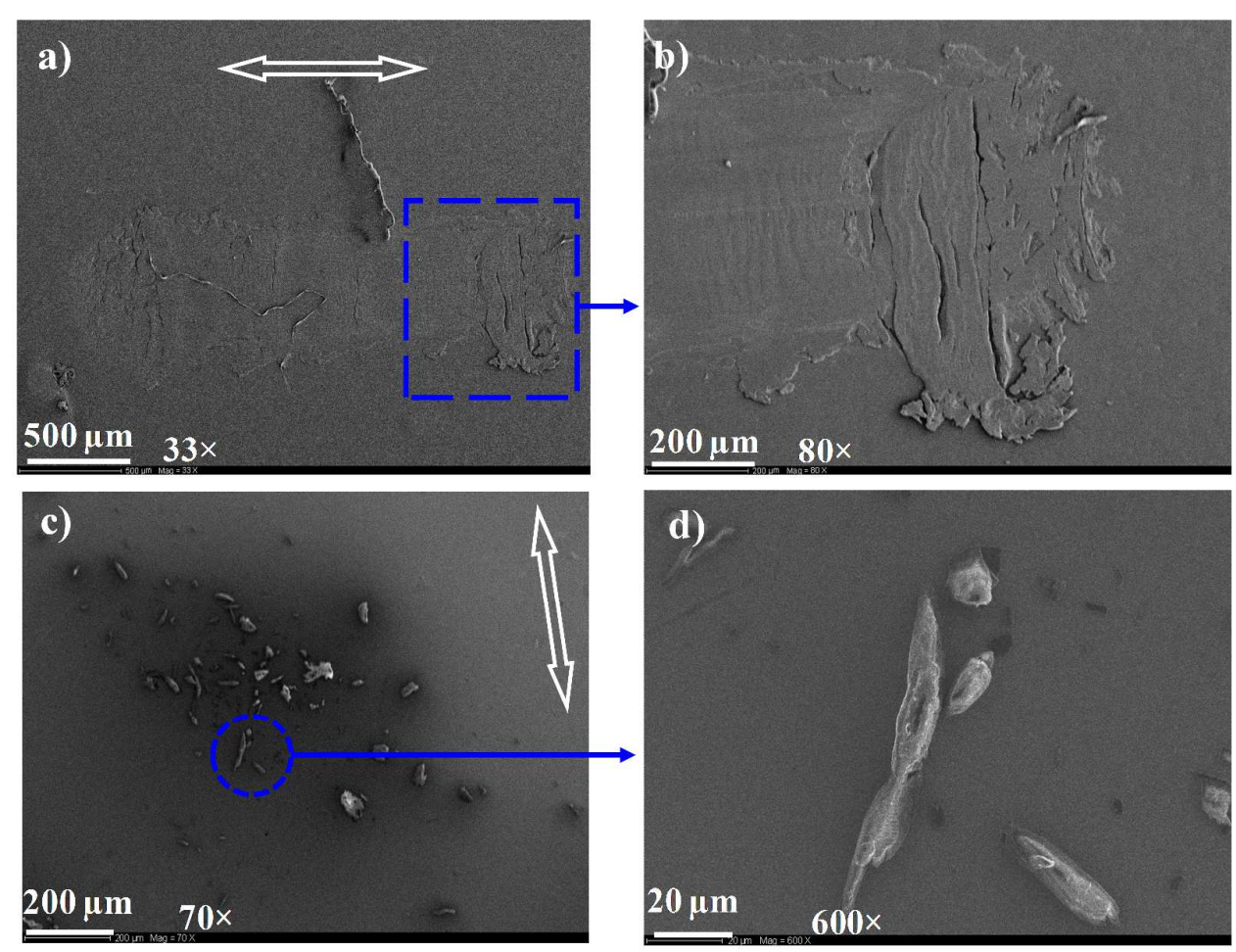

30

31

32

33

34

35

36

37

38

39

40

41

42

43

44

45

46

47

48

49

50

51

52

53

54

55

56

57

58

59

60

http://mc.manuscriptcentral.com/tandf/tribtrans, E-mail: FSadeghi@stle.org 


\section{Fig. 11}
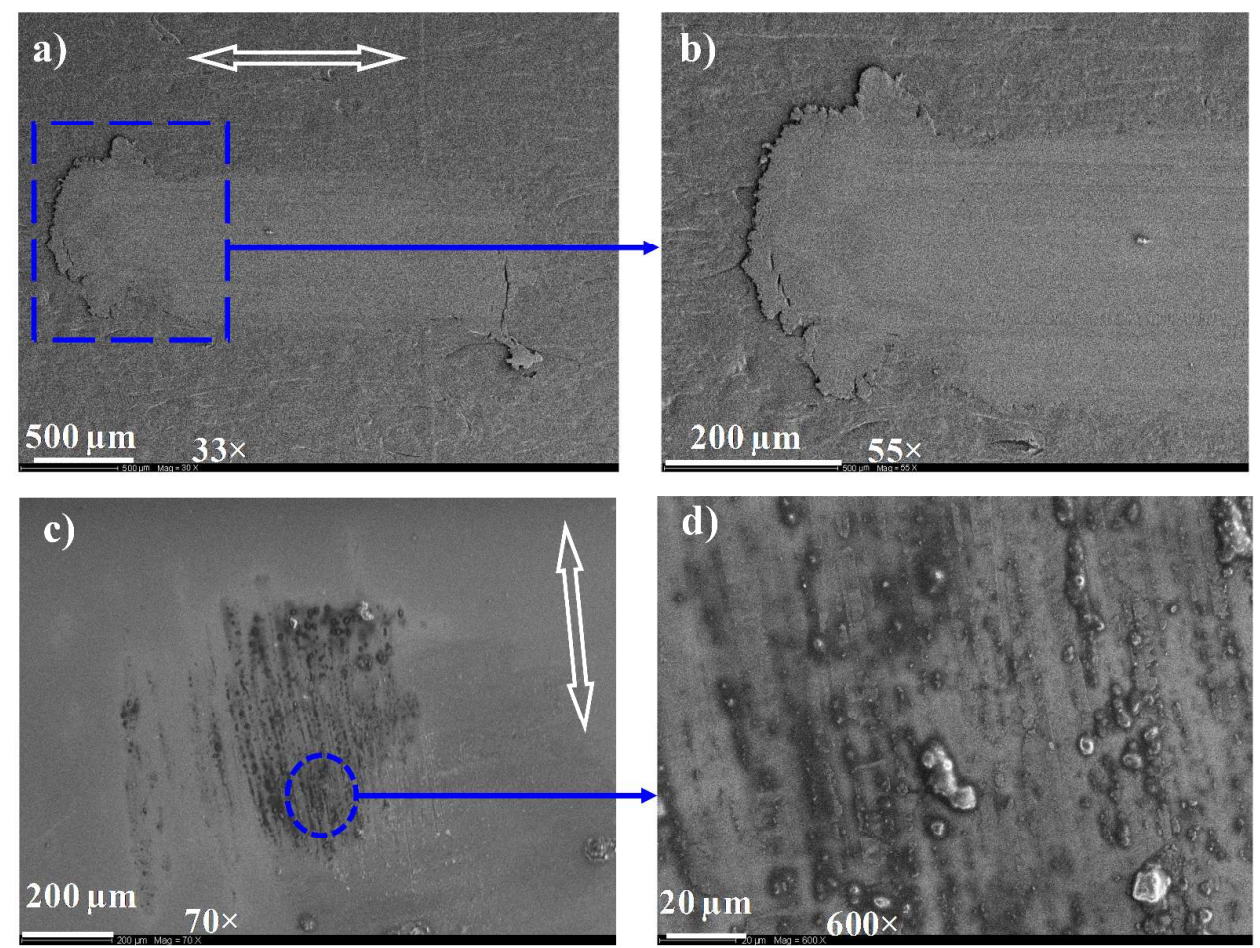
1

2

3

4

5

6

7

8

9

10

11

12

13

14

15

16

17

18

19

20

21

22

23

24

25

26

27

28

29

30

31

32

33

34

35

36

37

38

39

40

41

42

43

44

45

46

47

48

49

50

51

52

53

54

55

56

57

58

59

60

\section{Table 1}

\begin{tabular}{|l|c|}
\hline Injection pressure (bar) & 724 \\
\hline Injection temperature $\left({ }^{\circ} \mathrm{C}\right)$ & 290 \\
\hline Cycle time (s) & 31 \\
\hline Holding pressure (bar) & 310 \\
\hline Screw rotation speed $(\mathrm{mm} / \mathrm{s})$ & 220 \\
\hline
\end{tabular}

http://mc.manuscriptcentral.com/tandf/tribtrans, E-mail: FSadeghi@stle.org 
Table 2

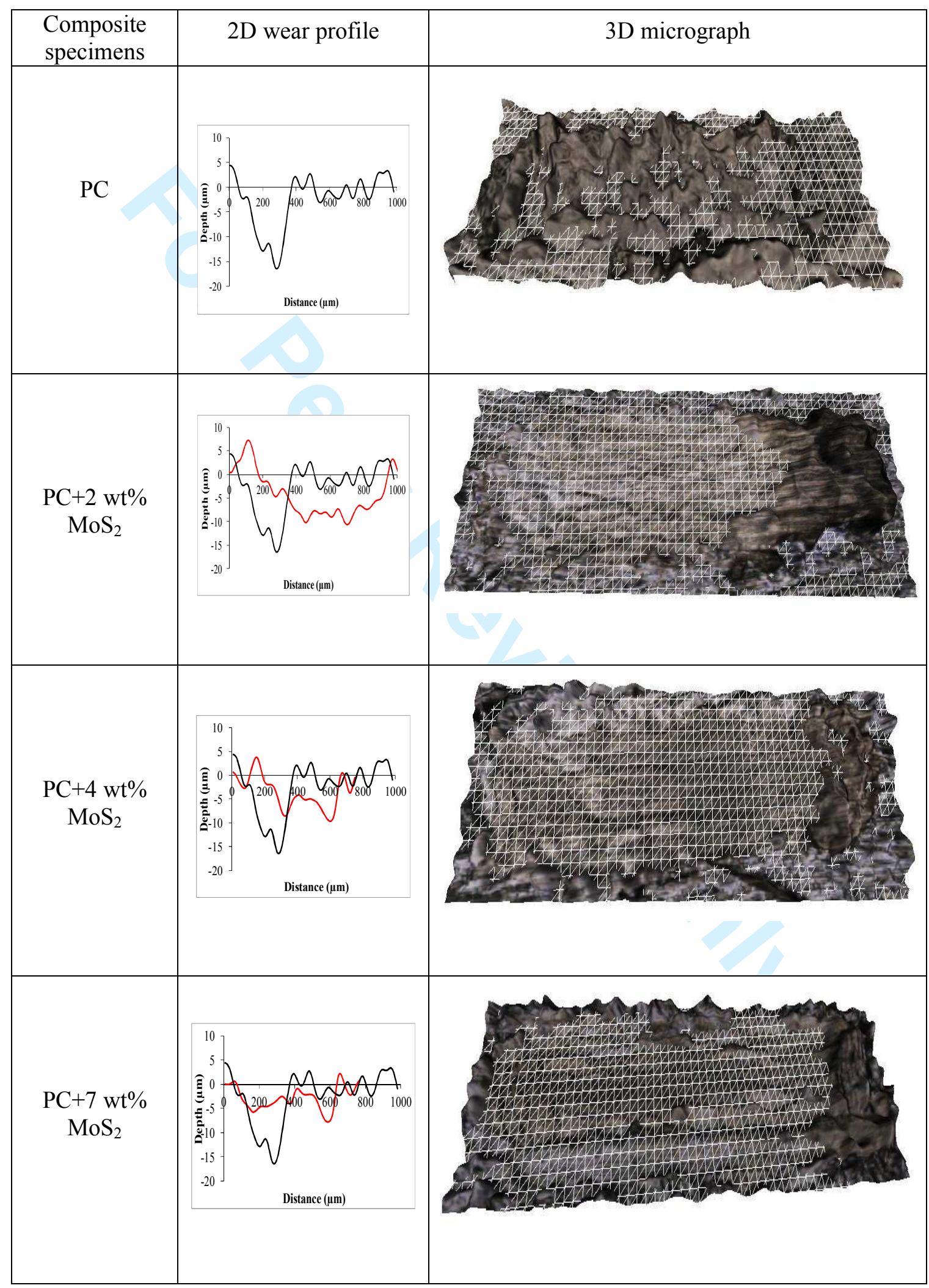

http://mc.manuscriptcentral.com/tandf/tribtrans, E-mail: FSadeghi@stle.org 


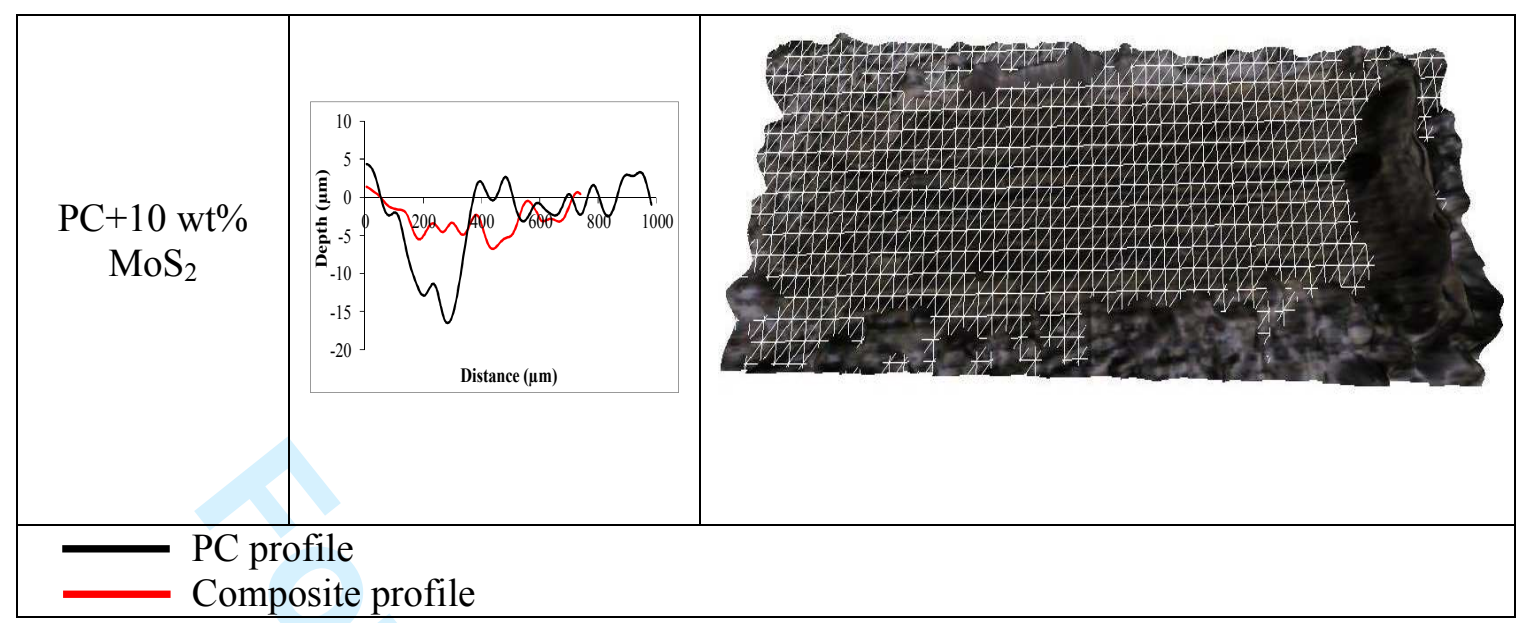

http://mc.manuscriptcentral.com/tandf/tribtrans, E-mail: FSadeghi@stle.org 